\title{
TINGKAT KEPUASAN MASYARAKAT TERHADAP PELAYANAN KEPOLISIAN RESOR BREBES
}

\author{
Jaka Waskito $^{1 *}$, Gunistiyo ${ }^{1}$, Dewi Indriasih ${ }^{1}$, Niken Wahyu $C^{1}$, Deddy Prihadi ${ }^{1}$ \\ ${ }^{1}$ Fakultas Ekonomi dan Bisnis, Universitas Pancasakti Tegal, Indonesia \\ *Email corresponding author: jaka_wsk@yahoo.co.id \\ Diterima 27/08/2020 Direvisi 28/09/2020 Diterbitkan 30/09/2020
}

\begin{abstract}
Abstrak
Survey penyusunan Indeks Kepuasan Masyarakat ini dilatarbelakangi oleh keingintahuan pihak lembaga kepolisian dalam memberikan pelayanan kepada masyarakat. Dilakukan dengan tujuan untuk mengetahui tingkat kinerja Kepolisian Resor Brebes dalam memberikan pelayanan kepada masyarakat dan sekaligus sebagai wahana penyerap aspirasi masyarakat baik yang berupa saran, harapan, sekaligus komplain terhadap pelayanan yang telah diberikan selama ini untuk dijadikan pedoman kebijakan, program dan strategi guna peningkatan pelayanan. Metode penilitian yang digunakan adalah penelitian kuantitatif yang bersifat deskriptif, yaitu pengolahan dan analisis dengan menggunakan pengolahan statistik sederhana yang berupa distribusi frekuensi. Berdasarkan hasil analisis data dan pembahasan diperoleh nilai hasil penelitian Indeks Kepuasan Masyarakat di Kepolisian Resor Kabupaten Brebes sebesar 81,30 dan berada pada katagori sangat baik. Agar prosedur, kejelasan, pengetahuan, keahlian dan keterampilan serta kesabaran para petugas pelayanan Polres Brebes lebih ditingkatkan lagi, sehingga dirasakan mampu dan memberikan kenyamanan bagi para pengguna layanan di Polres Brebes
\end{abstract}

Kata Kunci: Tingkat Kepuasan Masyarakat, Pelayanan, Kinerja Organisasi Pemerintah

\begin{abstract}
The survey for the preparation of the Community Satisfaction Index was motivated by the curiosity of the police agency in providing services to the community. Done with the aim of knowing the level of performance of the Brebes Resort Police in providing services to the community and at the same time as a vehicle for absorbing community aspirations in the form of suggestions, hopes, as well as complaints about the services that have been provided so far to be used as policy guidelines, programs and strategies for improving services. The research method used is descriptive quantitative research, namely processing and analysis using simple statistical processing in the form of frequency distribution. Based on the results of data analysis and discussion, it was found that the research value of the Community Satisfaction Index at the Brebes Regency Police was 81.30 and was in the very good category. In order to improve procedures, clarity, knowledge, expertise and skills as well as patience of the Brebes Police service officers, so that they feel capable and provide comfort for service users at the Brebes Police.

Keywords: Level of Community Satisfaction, Service, Performance of Government Organizations.
\end{abstract}

\section{PENDAHULUAN}

Penelitian ini dilatarbelakangi oleh keingintahuan pihak lembaga kepolisian di wilayah Polres Brebes dalam memberikan pelayanan kepada masyarakat. Harapannya dapat diketahui seberapa besar tingkat kepuasan masyarakat atas pelayanan kepolisian resor Brebes. Penyelenggaraan pelayanan publik merupakan salah satu fungsi penting pemerintah disamping distribusi, regulasi, dan proteksi. Fungsi tersebut merupakan aktualisasi riil kontrak sosial yang diberikan masyarakat kepada pemerintah dalam konteks hubungan Principal-Agent. 


\section{PERFORMANCE}

Jurnal Personalia, Financial, Operasional,

Marketing dau Sistem Informasi

Performance. Volume 27 Nomor 2 Tahun 2020, 62-75

Berdasarkan kerangka kerja tersebut, pemerintah selanjutnya melakukan proses pengaturan alokasi sumberdaya publik dengan cara menyeimbangkan aspek penerimaan dan pengeluaran untuk memaksimalisasi penyediaan kebutuhan pelayanan kolektif. Preskripsi tersebut hampir bertolak belakang dengan praksis pelayanan publik yang dimotori pemerintah, termasuk untuk konteks Indonesia kontemporer. Sebagai pelaksana kontrak sosial yang digariskan sebelumnya, pemerintah justru menimbulkan banyak masalah bagi publik yang menjadi kliennya. Sangat masuk akal jika pemerintah kemudian mendapat berbagai stigma negatif.

Dalam pendekatan fungsionalis untuk kepemimpinan publik, publikasi organisasi, terdiri dari studi teoritis dan empiris tentang persamaan dan perbedaan antara manajemen publik dan swasta yang secara khusus berkaitan dengan kepemimpinan publik (Tampubolon, 2020). Akan tetapi, upaya ke arah itu tampaknya masih mengalami banyak permasalahan serius, terutama menyangkut keberadaan sistem dan lembaga organisasi pemerintah yang masih belum sepenuhnya mampu mengembangkan sistem yang adaptif terhadap dinamika masyarakat. Birokrasi belum mampu mengadopsi nilai-nilai baru yang relevan dari dunia bisnis untuk memperbaiki kinerja pelayanan publik.

Keberhasilan kepolisian dalam membangun kinerja pelayanan yang efisien, responsif, dan akuntabel sebenarnya tergantung pada kepolisian dalam mengembangkan sistem pelayanan yang secara tepat mampu merefleksikan kondisi faktual lingkungannya. Kepolisian Resor (Polres) Brebes memberikan pelayanan masyarakat dalam urusan perizinan, informasi kegiatan masyarakat, pembuatan surat keterangan catatan kepolisian, penerbitan SIM dan sebagainya.

Penelitian ini menggunakan metode kuantitatif yang bersifat deskriptif karena dalam penelitian ini sifatnya survey yang diolah ke dalam bentuk indeks kepuasan dengan penghitungan Indeks Kepuasan Masyarakat (IKM).

\section{TINJAUAN PUSTAKA DAN PERUMUSAN HIPOTESIS}

\section{Hakekat Kepuasan Masyarakat}

Dalam kajian teoritis yang dilakukan oleh Mouw (2013) bahwa pelayanan publik di daerah menunjukkan manfaat dan keunggulannya, sekaligus juga menunjukkan kelemahannya. Harapan masyarakat yang selalu menginginkan kepuasan dalam pelayanan, namunkelemahan birokrat pada ketiadaan atau terbatasnya sumber daya yang mumpuni serta ditambah dengan peraturan-peraturan yang membuat birokrat daerah bekerja dengan kaku.Sehingga masih banyaknya keluhan masyarakat atas rendahnya kualitas pelayanan publik.

Lastriani (2014:358) menambahkan bahwa kinerja memiliki keterkaitan terhadap tujuan organisasi. Pegawai harus memberikan kontribusi kepada organisasi agar mencapai visi dan misi organisasi tersebut. Dari beberapa teori yang dikemukakan dapat dikatakan bahwa kepuasan masyarakat adalah respon, evaluasi, dan tingkat emosi masyarakat terhadap kualitas layanan yang telah dinikmati pada tingkat hasil (outcome) sama atau melewati batas penilaian presepsi masyarakat.

\section{Hakekat Kualitas Layanan}

Untuk melakukan pengukuran kualitas pelayanan, menurut Tjiptono (2011:26) dapat digunakan dimensi-dimensi kualitas pelayanan, yaitu bukti langsung (tangibles), kehandalan (reliability), daya tanggap (responsiveness), jaminan (assurance) dan empati (emphaty). Pengukuran ini dikenal sebagai service quality model. Pelayanan menekankan pada aspek kepuasan konsumen sehingga dapat menciptakan kesetiaan atau loyalitas kepada perusahaan yang telah memberikan kualitas pelayanan yang memuaskan. 
Performance. Volume 27 Nomor 2 Tahun 2020, 62-75

\section{Konsep Pelayanan Masyarakat}

Sebagai bukti bahwa lembaga kepolisian merupakan pengayom masyarakat, maka harus ada bukti yang nyata terhadap pelayanan kepada masyarakat sehingga bisa dirasakan secara langsung. Untuk itu, lembaga tersebut harus mumpuni dan handal dalam memberikan pelayanan sepenuhnya tanpa memandang status sosial masyarakat. Lembaga pelayanan publik harus mampu merespon dengan cepat dan mempunyai daya tanggap atas keluhan atau kebutuhan masyarakatnya. Selain itu yang tidak kalah pentingnya adalah bagaimana lembaga kepolisian sebagai pengayom bertanggung jawab atas tugas-tugas yang diembannya sekaligus diharapkan mendapatkan simpati dari masyarakat, sehingga mampu melakukan tugasnya seseuai dengan harapan masyarakat. Dengan demikian baik buruknya kualitas pelayanan sebenarnya tergantung juga kepada kemampuan penyedia layanan dalam memenuhi harapan masyarakat.

\section{Indeks Kepuasan Masyarakat}

Indeks Kepuasan Masyarakat adalah data dan informasi tentang tingkat kepuasan masyarakat yang diperoleh dari hasil pengukuran secara kuantitatif dan kualitatif atas pendapat masyarakat dalam memperoleh pelayanan dari aparatur penyelenggara pelayanan publik dengan membandingkan antara harapan dan kebutuhannya (Keputusan MENPAN Nomor 25/2004).

Berdasarkan prinsip pelayanan sebagaimana telah ditetapkan dalam Keputusan MENPAN Nomor 25 Tahun 2004, terdapat 14 unsur minimal yang harus ada untuk dasar pengukuran indeks kepuasan masyarakat antara lain prosedur pelayanan, persyaratan pelayanan, kejelasan petugas pelayanan, kedisiplinan petugas pelayanan, tanggung jawab petugas pelayanan, kemampuan petugas pelayanan, kecepatan pelayanan, keadilan mendapatkan pelayanan, kesopanan dan keramahan petugas, kewajaran biaya pelayanan, kepastian biaya pelayanan, kepastian jadwal pelayanan, kenyamanan lingkungan, keamanan pelayanan.

Polres Brebes sebagai salah satu instansi pemerintah yang berperan dalam penyelenggaraan pelayanan kepolisian kepada masyarakat dituntut untuk meningkatkan kualitas kinerja dalam memberikan pelayanan kepada masyarakat sehingga pelayanan yang diberikan mampu memenuhi kebutuhan, keinginan, dan harapan masyarakat serta mampu memberikan kepuasan. Berdasarkan Undang-undang Republik Indonesia Nomor 25 Tahun 2000 tentang Program Pembangunan Nasional (PROPENAS), salah satu upaya untuk meningkatkan kualitas pelayanan publik adalah dengan menyusun indeks kepuasan masyarakat sebagai tolok ukur untuk menilai tingkat kualitas pelayanan. Dengan demikian data indeks kepuasan masyarakat dapat menjadi bahan penilaian terhadap unsur pelayanan yang masih perlu perbaikan dan menjadi pendorong setiap unit penyelenggara pelayanan untuk meningkatkan kualitas pelayanannya.

\section{METODE PENELITIAN}

Jenis penelitian yang digunaan yaitu penelitian kuantitatif yang bersifat deskriptif, yaitu pengolahan dan analisis dengan menggunakan pengolahan statistik sederhana yang berupa distribusi frekuensi. Metode ini tidak membuktikan hipotesis, namun hanya menampilkan datadata dalam bentuk dekriptif sebagai gambaran dari hasil penelitian.

Lokasi penelitian berada di wilayah Hukum Polres Brebes yang meliputi Unit Penyelenggara Pelayanan Polres Brebes Kabupaten Brebes. Sebagai populasi dalam penelitian ini adalah seluruh masyarakat di daerah Kabupaten Brebes yang mendapatkan pelayanan yang dilakukan oleh seluruh jajaran Polres Brebes. Sedangkan sampel di ambil di Unit Penyelenggara Pelayanan Polres Brebes dengan obyek survey meliputi Satuan Interkam (Pelayanan SKCK, Pelayanan Perijinan), Satuan Lalu Lintas (Pelayanan SIM, Pelayanan STNK dan TNKB, Pelayaanan BPKB, 


\section{PERFORMANCE}

Jurnal Personalia, Financial, Operasional,

Marketing dau Sistem Informasi

Performance. Volume 27 Nomor 2 Tahun 2020, 62-75

Pelayanan Kecelakaan Lalu Lintas), SPKT (Pelayanan Pengaduan Masyarakat, Pelayanan Laporan Polisi, Pelayanan Pembuatan Surat Keterangan Kehilangan, Reskrim, Pelayanan Sidik Jari, Pelayanan Penyidikan Tindak Pidana).

Sampel/Responden dipilih acak, untuk memenuhi akurasi hasil penyusunan indeks, responden terpilih ditetapkan minimal 150 orang dari jumlah populasi penerima pelayanan, dengan dasar (Jumlah Unsur +1$) \times 10=$ Jumlah Responden $(14+1) \times 10=150$ responden (Surat Keputusan MENPAN Nomor 25 Tahun 2004). Penggunaan pengambilan sampel ini disesuaikan dengan Surat Keputusan MENPAN Nomor 25 Tahun 2004 karena objek dalam penelitian ini adalah lembaga pemerintah. Alat analisis yang digunakan adalah:

\section{Uji Validitas dan Reliabilitas}

Validitas menunjukkan sejauh mana suatu alat ukur itu mengukur apa yang ingin diukur. Sekiranya peneliti menggunakan kuesioner didalam pengumpulan data, maka kuesioner yang disusunnya harus mengukur apa yang ingin diukurnya. Setelah kuesioner tersebut tersusun dan teruji validitasnya, dalam praktek belum tentu data yang terkumpulkan adalah data yang valid.

Menurut Sugiyono (2017:177) mengemukakan bahwa: "Instrumen yang valid berarti alat ukur yang digunakan untuk mendapatkan data (mengukur) itu valid". Dalam pengujian validitas ini dilakukan dengan analisis item yaitu mengkorelasikan skor tiap butir dengan skor total yang merupakan jumlah tiap skor butir.

\section{Penghitungan Indeks Kepuasan Masyarakat (IKM)}

Kuesioner yang masuk akan diolah dalam data entri komputer untuk mendapat IKM nya. Nilai IKM dihitung dengan menggunakan "Nilai rata -rata tertimbang" masing-masing unsur pelayanan, dalam menghitung indeks kepuasan masyarakat tehadap 14 unsur pelayanan yang dikaji, setiap unsur pelayanan memiliki penimbang yang sama dengan memakai rumus sebagai berikut:

$$
\text { Bobot nilai rata }- \text { rata tertombang }=\frac{1}{14}=0,071
$$

Untuk memperoleh nilai IKM unit pelayanan digunakan pendekatan nilai rata-rata tertimbang $(0,071)$ dengan rumus sebagai berikut :

$$
I K M=\frac{\text { Total dari nilai persepsi per unsur }}{\text { Total unsur yang terisi }} \times \text { Nilai Penimbang }
$$

Tingkat kesesuaian adalah hasil perbandingan skor penilaian pelaksanaan/kinerja dengan skor penilaian tingkat kepentingan. Adapun rumus tingkat kesesuaian adalah sebagai berikut:

$$
T k i=\frac{X i}{Y i} \times 100 \%
$$

\section{Teknik Analisis}

Untuk menganalisis data, peneliti menggunakan model analisis kuantitatif deskriptif, yaitu pengolahan dan analisa dengan menggunakan pengolahan statistik sederhana yang berupa distribusi frekuensi. Distribusi yang telah terbentuk selanjutnya dinterpretasikan guna menajamkan pembahasan atau analisa dari penelitian ini.

Hasil analisis terhadap penilaian indeks kepuasan masyarakat melalui kuesioner yang sudah disebar kepada 150 responden menunjukkan bahwa nilai IKM yang akan menunjukkan kinerja dari unit pelayanan dengan kriteria sebagai berikut: 
Jurnal Personalia, Financial, Operasional,

Marketing dam Sistern Informasi

Performance. Volume 27 Nomor 2 Tahun 2020, 62-75

Tabel 1. Kriteria Penilaian Kinerja Unit Pelayanan

\begin{tabular}{ccccc}
\hline $\begin{array}{c}\text { Nilai } \\
\text { Persepsi }\end{array}$ & $\begin{array}{c}\text { Nilai Interval } \\
\text { IKM }\end{array}$ & $\begin{array}{c}\text { Nilai Interval } \\
\text { Konversi IKM }\end{array}$ & $\begin{array}{c}\text { Mutu } \\
\text { Pelayanan }\end{array}$ & $\begin{array}{c}\text { Kinerja Unit } \\
\text { Pelayanan }\end{array}$ \\
\hline 1 & $1,00-1,75$ & $25,00-43,75$ & D & Tidak Baik \\
\hline 2 & $1,76-2,50$ & $43,76-62,50$ & C & Kurang Baik \\
\hline 3 & $2,51-3,25$ & $62,51-81,25$ & B & Baik \\
\hline 4 & $3,26-4,00$ & $81,26-100,00$ & A & Sangat Baik \\
\hline
\end{tabular}

Sumber: Surat Keputusan MENPAN Nomor 25 Tahun 2004

\section{HASIL DAN PEMBAHASAN}

\section{Uji Validitas Instrumen}

Sesuai dengan metode pengumpulan data yang digunakan, maka instrument pokok yang digunakan dalam penelitian ini adalah kuesioner. Tujuan pengumpulan data dengan menggunakan kuesioner adalah untuk memperoleh informasi yang relevan dengan tujuan penelitian, serta memiliki tingkat keandalan (reliability) dan keabsahan atau validitas (validity) setinggi mungkin. Oleh karena itu syarat suatu instrument penelitian untuk dapat digunakan dalam pengumpulan data penelitian dengan baik adalah instrument tersebut harus memiliki validitas dan reliabilitas yang tinggi. Validitas adalah suatu alat ukur yang menunjukan tingkat kevalidan dan kesahihan suatu instrument.

Suatu instrumen dikatakan valid apabila mampu mengukur apa yang diinginkan dan dapat mengungkap data variabel yang diteliti secara tepat. Sedangkan reabilitas adalah suatu pengujian untuk menunjukan sejauh mana alat ukur dapat dipercaya atau dihandalkan atau tingkat konsistensi dari suatu instrumen apabila dilakukan pengujian secara berulang-ulang. Uji ini dilakukan untuk mengetahui validitas butir-butir pertanyaan dapat dilihat pada kolom yang merupakan $\mathbf{r}_{\text {hitung }}$ untuk masing-masing pertanyaan. Apabila nilai $\boldsymbol{r}_{\text {hitung }}$ lebih besar dari $\boldsymbol{r}_{\text {tabel, }}$ maka butir-butir pertanyaan tersebut dapat dikatakan valid.

Tabel 2. Hasil Uji Validitas Instrumen IKM

\begin{tabular}{cccc}
\hline Pertanyaan & $r_{\text {hitung }}$ & $r_{\text {tabel }}$ & Kriteria \\
\hline P1 & 0,532 & 0,361 & Valid \\
P2 & 0,644 & 0,361 & Valid \\
P3 & 0,668 & 0,361 & Valid \\
P4 & 0,668 & 0,361 & Valid \\
P5 & 0,701 & 0,361 & Valid \\
P6 & 0,860 & 0,361 & Valid \\
P7 & 0,393 & 0,361 & Valid \\
P8 & 0,736 & 0,361 & Valid \\
P9 & 0,769 & 0,361 & Valid \\
P10 & 0,560 & 0,361 & Valid \\
P11 & 0,732 & 0,361 & Valid \\
P12 & 0,649 & 0,361 & Valid \\
P13 & 0,716 & 0,361 & Valid \\
P14 & 0,820 & 0,361 & Valid \\
\hline
\end{tabular}

Sumber: Data primer yang diolah, 2019 
Jurnal Personalia, Financial, Operasional,

Marketing dau Sistem Informasi

Performance. Volume 27 Nomor 2 Tahun 2020, 62-75

Dari hasil pengujian validitas pertanyaan di atas dapat diketahui bahwa semua butir pernyataan dalam kuesioner adalah valid, karena mempunyai $r_{\text {hitung }}$ lebih besar dari $r_{\text {tabel }}(n=30)$ $=0,361$. Maka dapat diambil kesimpulan, bahwa seluruh keseluruhan butir pertanyaan instrument IKM yang digunakan dalam penelitian ini layak digunakan dalam penelitian dan dinyatakan valid.

\section{Uji Reliabilitas}

Reliabilitas adalah kesamaan hasil pengukuran atau pengamatan bila diukur atau diamati berkali-kali dalam waktu yang berlainan. Dalam kuesioner dikatakan reliabel atau handal jika jawaban seseorang terhadap pertanyaan adalah konsisten atau stabil dari waktu ke waktu. Uji reabilitas dilakukan dengan menggunakan Cronbach Alpha $(\alpha)$. Suatu konstruk dikatakan reliabel jika memberikan nilai koefisien Alpha lebih besar daripada 0,70. Dari hasil perhitungan reliabilitas instrument IKM diketahui nilai alpha conbrach sebesar 0,906. Karena nilai alpha conbrach sebesar 0,906>0,7 maka butir angket instrument IKM dinyatakan reliabel dan dapat digunakan untuk penelitian. Hasil uji reliabilitas dalam penelitian ini dapat dilihat pada tabel sebagai berikut:

Tabel 3. Hasil Uji Reliabilitas Instrumen IKM

Case Processing Summary

\begin{tabular}{rlcr}
\hline & & N & $\%$ \\
\hline Cases & Valid & 30 & 100,0 \\
\hline & Excluded $^{a}$ & 0 &, 0 \\
\hline & Total & 30 & 100,0 \\
\hline
\end{tabular}

a. Listwise deletion based on all variables in the procedure

Reliability Statistics

\begin{tabular}{c|c}
\hline Cronbanch's Alpha & N of Items \\
\hline, 906 & 14 \\
\hline
\end{tabular}

\section{Analisis Data Penelitian}

\section{Distribusi Data Pertanyaan Prosedur Pelayanan}

Hasil analisis pada ruang lingkup Prosedur Pelayanan secara detail disajikan dalam tabel berikut ini :

Tabel 4. Pendapat Responden tentang Prosedur Pelayanan

\begin{tabular}{llrrrr}
\hline & Frequency & Percent & Valid Percent & Cumulative Percent \\
\hline \multirow{2}{*}{ Valid } & Tidak Mudah & 0 & 0,00 & 0,00 & 0,00 \\
& Kurang Mudah & 6 & 4,00 & 4,00 & 4,00 \\
& Mudah & 98 & 65,33 & 65,33 & 69,33 \\
Sangat Mudah & 46 & 30,67 & 30,67 & 100,00 \\
\hline
\end{tabular}

Sumber : Data primer, diolah 2019

Tabel tersebut menunjukkan bahwa mayoritas responden menyatakan Prosedur Pelayanan di Polres Brebes Mudah (65,33\%). Nilai unsur butir pertanyaan tentang prosedur pelayanan sebesar 490 dengan nilai rata rata per unsur sebesar $3,27 \times 25=81,67$. Dengan demikian di peroleh Nilai IKM butir pertanyaan tentang Prosedur Pelayanan di Polres Brebes sebesar 81,67 pada kreteria Sangat Baik. Prosedur pelayanannya dirasakan masyarakat sangat mudah. 
Distribusi Data Pertanyaan Persyaratan Pelayanan

Hasil analisis pada ruang lingkup Persyaratan Pelayanan secara detail disajikan dalam tabel berikut ini :

Tabel 5. Pendapat Responden tentang Persyaratan Pelayanan

\begin{tabular}{llrrrr}
\hline & Frequency & Percent & Valid Percent & Cumulative Percent \\
\hline Valid & Tidak Sesuai & 0 & 0,00 & 0,00 & 0,00 \\
& Kurang Sesuai & 4 & 2,67 & 2,67 & 2,67 \\
& Sesuai & 110 & 73,33 & 73,33 & 76,00 \\
Sangat Sesuai & 36 & 24,00 & 24,00 & 100,00 \\
\hline
\end{tabular}

Sumber : Data primer, diolah 2019

Tabel tersebut menunjukkan bahwa mayoritas responden menyatakan Persyaratan Pelayanan di Polres Brebes Sesuai (73,33\%). Nilai unsur butir pertanyaan tentang persyaratan pelayanan sebesar 482 dengan nilai rata rata per unsur sebesar $3,21 \times 25=80,33$. Dengan demikian di peroleh Nilai IKM butir pertanyaan tentang Prosedur Pelayanan di Polres Brebes sebesar 80,33 pada kreteria Baik. Responden merasakan adanya kesesuaian antara persyaratan dengan kenyataan.

\section{Distribusi Data Pertanyaan Kejelasan Petugas Pelayanan}

Hasil analisis pada ruang lingkup Kejelasan Petugas Pelayanan secara detail disajikan dalam tabel berikut ini :

Tabel 6. Pendapat Responden tentang Kejelasan Petugas Pelayanan

\begin{tabular}{llrrrr}
\hline & Frequency & & Percent & Valid Percent & Cumulative Percent \\
\hline \multirow{2}{*}{ Valid } & Tidak jelas & 0 & 0,00 & 0,00 & 0,00 \\
& Kurang jelas & 6 & 4,00 & 4,00 & 4,00 \\
& Jelas & 97 & 64,67 & 64,67 & 68,67 \\
& Sangat jelas & 47 & 31,33 & 31,33 & 100,00 \\
\hline
\end{tabular}

Sumber : Data primer, diolah 2019

Tabel tersebut menunjukkan bahwa mayoritas responden menyatakan Kejelasan Petugas Pelayanan di Polres Brebes Jelas (64,67\%). Nilai unsur butir pertanyaan tentang kejelasan petugas pelayanan sebesar 491 dengan nilai rata rata per unsur sebesar 3,27 X $25=81,83$. Dengan demikian di peroleh Nilai IKM butir pertanyaan tentang Kejelasan Petugas Pelayanan di Polres Brebes sebesar 81,83 pada kreteria Sangat Baik. Responden merasakan ada kejelasan dari petugasan yang melayani.

\section{Distribusi Data Pertanyaan Kedisiplinan Petugas Pelayanan}

Hasil analisis pada ruang lingkup Kedisiplinan Petugas Pelayanan secara detail disajikan dalam tabel berikut ini : 
Jurnal Personalia, Financial, Operasional,

Marketing dau Sistem Informasi

Performance. Volume 27 Nomor 2 Tahun 2020, 62-75

Tabel 7. Pendapat Responden tentang Kedisiplinan Petugas Pelayanan

\begin{tabular}{llrrrr}
\hline & Frequency & & Percent & Valid Percent & Cumulative Percent \\
\hline Valid & Tidak disiplin & 0 & 0,00 & 0,00 & 0,00 \\
& Kurang disiplin & 4 & 2,67 & 2,67 & 2,67 \\
& Disiplin & 103 & 68,67 & 68,67 & 71,33 \\
& Sangat disiplin & 43 & 28,67 & 28,67 & 100,00 \\
\hline Total & 150 & 100 & 100 & \\
\hline
\end{tabular}

Sumber : Data primer, diolah 2019

Tabel tersebut menunjukkan bahwa mayoritas responden menyatakan Kedisiplinan Petugas Pelayanan di Polres Brebes Disiplin (68,67\%). Nilai unsur butir pertanyaan tentang kedisiplinan petugas pelayanan sebesar 489 dengan nilai rata rata per unsur sebesar 3,26 $\times 25=$ 81,50. Dengan demikian di peroleh Nilai IKM butir pertanyaan tentang Disiplin Petugas Pelayanan di Polres Brebes sebesar 81,50 pada kreteria Sangat Baik. Petugas dirasakan responden sangat disiplin dalam melayani masyarakat pengguna.

Distribusi Data Pertanyaan Tanggung Jawab Petugas Pelayanan

Hasil analisis pada ruang lingkup Tanggung Jawab Petugas Pelayanan secara detail disajikan dalam tabel berikut ini :

Tabel 8. Pendapat Responden tentang Tanggung Jawab Petugas Pelayanan

\begin{tabular}{llrrrr}
\hline & Frequency & & Percent & Valid Percent & Cumulative Percent \\
\hline Valid & Tidak bertanggung jawab & 0 & 0,00 & 0,00 & 0,00 \\
& Kurang bertanggung jawab & 2 & 1,33 & 1,33 & 1,33 \\
Bertanggung jawab & 105 & 70,00 & 70,00 & 71,33 \\
Sangat bertanggung jawab & 43 & 28,67 & 28,67 & 100,00 \\
\hline Total & 150 & 100 & 100 & \\
\hline
\end{tabular}

Sumber : Data primer, diolah 2019

Tabel tersebut di atas menunjukkan bahwa mayoritas responden menyatakan Tanggung Jawab Petugas Pelayanan di Polres Brebes Bertanggung Jawab (70,00\%). Nilai unsur butir pertanyaan tentang tanggung jawab petugas pelayanan sebesar 491 dengan nilai rata rata per unsur sebesar 3,27 X $25=81,83$. Dengan demikian di peroleh Nilai IKM butir pertanyaan tentang Tanggung Jawab Petugas Pelayanan di Polres Brebes sebesar 81,83 pada kreteria Sangat Baik. Responden menilai petugas sangat bertanggung jawab dalam menjalankan tugasnya.

\section{Distribusi Data Pertanyaan Kemampuan Petugas Pelayanan}

Hasil analisis pada ruang lingkup Kemampuan Petugas Pelayanan secara detail disajikan dalam tabel berikut ini : 
Jurnal Personalia, Financial, Operasional,

Marketing dam Sistem Informasi

Performance. Volume 27 Nomor 2 Tahun 2020, 62-75

Tabel 9. Pendapat Responden tentang Kemampuan Petugas Pelayanan

\begin{tabular}{llrrrr}
\hline & Frequency & \multicolumn{2}{c}{ Percent } & Valid Percent & Cumulative Percent \\
\hline Valid & Tidak mampu & 0 & 0,00 & 0,00 & 0,00 \\
& Kurang mampu & 0 & 0,00 & 0,00 & 0,00 \\
& Mampu & 98 & 65,33 & 65,33 & 65,33 \\
& Sangat mampu & 52 & 34,67 & 34,67 & 100,00 \\
\hline Total & 150 & 100 & 100 & \\
\hline
\end{tabular}

Sumber : Data primer, diolah 2019

Tabel tersebut menunjukkan bahwa mayoritas responden menyatakan Kemampuan Petugas Pelayanan di Polres Brebes Mampu (65,33\%). Nilai unsur butir pertanyaan tentang kemampuan petugas pelayanan sebesar 502 dengan nilai rata rata per unsur sebesar 3,35 X 25 $=83,67$. Dengan demikian di peroleh Nilai IKM butir pertanyaan tentang Kemampuan Petugas Pelayanan di Polres Brebes sebesar 83,67 pada kreteria Sangat Baik. Responden menilai petugas mempunyai kemampuan di unitnya.

\section{Distribusi Data Pertanyaan Kecepatan Pelayanan}

Hasil analisis pada ruang lingkup Kecepatan Pelayanan secara detail disajikan dalam tabel berikut ini :

Tabel 10. Pendapat Responden tentang Kecepatan Pelayanan

\begin{tabular}{llrrrr}
\hline & Frequency & Percent & Valid Percent & Cumulative Percent \\
\hline Valid & Tidak cepat & 0 & 0,00 & 0,00 & 0,00 \\
& Kurang cepat & 20 & 13,33 & 13,33 & 13,33 \\
& Cepat & 93 & 62,00 & 62,00 & 75,33 \\
& Sangat cepat & 37 & 24,67 & 24,67 & 100,00 \\
\hline Total & 150 & 100 & 100 & \\
\hline
\end{tabular}

Sumber : Data primer, diolah 2019

Tabel tersebut menunjukkan bahwa mayoritas responden menyatakan Kecepatan Pelayanan di Polres Brebes Cepat (62,00\%). Nilai unsur butir pertanyaan tentang kecepatan pelayanan sebesar 467 dengan nilai rata rata per unsur sebesar 3,11 X $25=77,83$. Dengan demikian di peroleh Nilai IKM butir pertanyaan tentang Kecepatan Pelayanan di Polres Brebes sebesar 77,83 pada kreteria Baik. Responden merasakan dalam pelayanannya cepat.

\section{Distribusi Data Pertanyaan Keadilan mendapatkan Pelayanan}

Hasil analisis pada ruang lingkup Keadilan mendapatkan Pelayanan secara detail disajikan dalam tabel berikut ini :

Tabel 11. Pendapat Responden tentang Keadilan mendapatkan Pelayanan

\begin{tabular}{llrrrr}
\hline & Frequency & \multicolumn{2}{c}{ Percent } & Valid Percent & Cumulative Percent \\
\hline Valid & Tidak adil & 0 & 0,00 & 0,00 & 0,00 \\
& Kurang adil & 1 & 0,67 & 0,67 & 0,67 \\
& Adil & 112 & 74,67 & 74,67 & 75,33 \\
& Sangat adil & 37 & 24,67 & 24,67 & 100,00 \\
\hline & Total & 150 & 100 & 100 &
\end{tabular}

Sumber : Data primer, diolah 2019 
Jurnal Personalia, Financial, Operasional,

Marketing dau Sistem Informasi

Performance. Volume 27 Nomor 2 Tahun 2020, 62-75

Tabel tersebut menunjukkan bahwa mayoritas responden menyatakan Keadilan mendapatkan Pelayanan di Polres Brebes Adil (74,67\%). Nilai unsur butir pertanyaan tentang keadilan mendapatkan pelayanan sebesar 482 dengan nilai rata rata per unsur sebesar 3,24 X $25=80,00$. Dengan demikian di peroleh Nilai IKM butir pertanyaan tentang Keadilan mendapatkan Pelayanan di Polres Brebes sebesar 80,00 pada kreteria Baik. Menurut pengguna, ada keadilan petugas dalam melayani.

\section{Distribusi Data Pertanyaan Kesopanan dan Keramahan Petugas Pelayanan}

Hasil analisis pada ruang lingkup Kesopanan dan Keramahan Petugas Pelayanan secara detail disajikan dalam tabel berikut ini :

Tabel 12. Pendapat Responden tentang Kesopanan dan Keramahan Petugas Pelayanan

\begin{tabular}{llrrrr}
\hline & Frequency & \multicolumn{2}{c}{ Percent } & Valid Percent & Cumulative Percent \\
\hline Valid & Tidak sopan \& ramah & 0 & 0,00 & 0,00 & 0,00 \\
& Kurang sopan \& ramah & 3 & 2,00 & 2,00 & 2,00 \\
Sopan \& ramah & 92 & 61,33 & 61,33 & 63,33 \\
Sangat sopan \& ramah & 55 & 36,67 & 36,67 & 100,00 \\
\hline Total & 150 & 100 & 100 & \\
\hline
\end{tabular}

Sumber : Data primer, diolah 2019

Tabel tersebut menunjukkan bahwa mayoritas responden menyatakan Kesopanan dan Keramahan Petugas Pelayanan di Polres Brebes Sopan dan Ramah (61,33\%). Nilai unsur butir pertanyaan tentang kesopanan dan keramahan kesebesar 502 dengan nilai rata rata per unsur sebesar 3,35 X $25=83,67$. Dengan demikian di peroleh Nilai IKM butir pertanyaan tentang Kesopanan dan Keramahan Pelayanan di Polres Brebes sebesar 83,67 pada kreteria Sangat Baik. Responden merasakan petugas sangat sopan dalam melayani.

\section{Distribusi Data Pertanyaan Kewajaran Biaya Pelayanan}

Hasil analisis pada ruang lingkup Kewajaran Biaya Pelayanan secara detail disajikan dalam tabel berikut ini :

Tabel 13. Pendapat Responden tentang Kewajaran Biaya Pelayanan

\begin{tabular}{llrrrr}
\hline & Frequency & & Percent & Valid Percent & Cumulative Percent \\
\hline \multirow{2}{*}{ Valid } & Tidak wajar & 0 & 0,00 & 0,00 & 0,00 \\
& Kurang wajar & 5 & 3,33 & 3,33 & 3,33 \\
& Wajar & 115 & 76,67 & 76,67 & 80,00 \\
Sangat wajar & 30 & 20,00 & 20,00 & 100,00 \\
\hline Total & 150 & 100 & 100 & \\
\hline
\end{tabular}

Sumber : Data primer, diolah 2019

Tabel tersebut menunjukkan bahwa mayoritas responden menyatakan Kewajaran Biaya Pelayanan di Polres Brebes Wajar (76,67\%). Nilai unsur butir pertanyaan tentang kewajaran biaya pelayanan sebesar 475 dengan nilai rata rata per unsur sebesar 3,17 X $25=79,17$. Dengan demikian di peroleh Nilai IKM butir pertanyaan tentang Kewajaran Biaya Pelayanan di Polres Brebes sebesar 79,17 pada kreteria Baik. Menurut responden, ada kewajaran biaya dalam administrasi. 
Jurnal Personalia, Financial, Operasional,

Marketing dau Sistern Informasi

Performance. Volume 27 Nomor 2 Tahun 2020, 62-75

Distribusi Data Pertanyaan Kepastian Biaya Pelayanan

Hasil analisis pada ruang lingkup Kepastian Biaya Pelayanan secara detail disajikan dalam tabel berikut ini :

Tabel 14. Pendapat Responden tentang Kepastian Biaya Pelayanan

\begin{tabular}{llrrrr}
\hline & Frequency & \multicolumn{2}{c}{ Percent } & Valid Percent & Cumulative Percent \\
\hline \multirow{2}{*}{ Valid } & Selalu tidak sesuai & 0 & 0,00 & 0,00 & 0,00 \\
& Kadang-kadang sesuai & 14 & 9,33 & 9,33 & 9,33 \\
& Banyak sesuainya & 75 & 50,00 & 50,00 & 59,33 \\
Selalu sesuai & 61 & 40,67 & 40,67 & 100,00 \\
\hline
\end{tabular}

Sumber : Data primer, diolah 2019

Tabel tersebut di atas menunjukkan bahwa mayoritas responden menyatakan Kepastian Biaya Pelayanan di Polres Brebes Banyak sesuainya (50,00\%). Nilai unsur butir pertanyaan tentang kepastian biaya pelayanan sebesar 497 dengan nilai rata rata per unsur sebesar 3,31 X $25=82,83$. Dengan demikian di peroleh Nilai IKM butir pertanyaan tentang Kepastian Biaya Pelayanan di Polres Brebes sebesar 82,83 pada kreteria Sangat Baik. Responden merasakan bahwa biaya yang dikenakan sesuai dengan yang dicantumkan.

Distribusi Data Pertanyaan Kepastian Jadwal Pelayanan

Hasil analisis pada ruang lingkup Kepastian Jadwal Pelayanan secara detail disajikan dalam tabel berikut ini :

Tabel 15. Pendapat Responden tentang Kepastian Jadwal Pelayanan

\begin{tabular}{llrrrr}
\hline & Frequency & & Percent & Valid Percent & Cumulative Percent \\
\hline Valid & Selalu tidak tepat & 0 & 0,00 & 0,00 & 0,00 \\
& Kadang-kadang tepat & 15 & 10,00 & 10,00 & 10,00 \\
& Banyak tepatnya & 66 & 44,00 & 44,00 & 54,00 \\
Selalu tepat & 69 & 46,00 & 46,00 & 100,00 \\
\hline Total & 150 & 100 & 100 & \\
\hline
\end{tabular}

Sumber : Data primer, diolah 2019

Tabel tersebut di atas menunjukkan bahwa mayoritas responden menyatakan Kepastian Jadwal Pelayanan di Polres Brebes Selalu Tepat (46,00\%). Nilai unsur butir pertanyaan tentang kepastian jadwal pelayanan sebesar 504 dengan nilai rata rata per unsur sebesar 3,36 X $25=$ 84,00 . Dengan demikian di peroleh Nilai IKM butir pertanyaan tentang Kepastian Jadwal Pelayanan di Polres Brebes sebesar 84,00 pada kreteria Sangat Baik. Responden merasakan ada ketepatan dalam jadwal pelayanan.

\section{Distribusi Data Pertanyaan Kenyamanan Lingkungan Pelayanan}

Hasil analisis pada ruang lingkup Kenyamanan Lingkungan Pelayanan secara detail disajikan dalam tabel berikut ini : 
Jurnal Personalia, Financial, Operasional,

Marketing dau Sistem Informasi

Performance. Volume 27 Nomor 2 Tahun 2020, 62-75

Tabel 16. Pendapat Responden tentang Kenyamanan Lingkungan Pelayanan

\begin{tabular}{llrrrr}
\hline & Frequency & \multicolumn{2}{c}{ Percent } & Valid Percent & Cumulative Percent \\
\hline Valid & Tidak nyaman & 0 & 0,00 & 0,00 & 0,00 \\
& Kurang nyaman & 11 & 7,33 & 7,33 & 7,33 \\
& Nyaman & 86 & 57,33 & 57,33 & 64,67 \\
& Sangat nyaman & 53 & 35,33 & 35,33 & 100,00 \\
\hline & Total & 150 & 100 & 100 & \\
\hline
\end{tabular}

Sumber : Data primer, diolah 2019

Tabel tersebut di atas menunjukkan bahwa mayoritas responden menyatakan Kenyamanan Lingkungan Pelayanan di Polres Brebes Nyaman (57,33\%). Nilai unsur butir pertanyaan tentang kenyamanan lingkungan pelayanan sebesar 492 dengan nilai rata rata per unsur sebesar 3,28 X $25=82,00$. Dengan demikian di peroleh Nilai IKM butir pertanyaan tentang Kenyamanan Lingkungan Pelayanan di Polres Brebes sebesar 82,00 pada kreteria Sangat Baik. Pengguna pelayanan merasakan adanya kenyamanan di lingkungan Polres Brebes.

\section{Distribusi Data Pertanyaan Keamanan Pelayanan}

Hasil analisis pada ruang lingkup Keamanan Pelayanan secara detail disajikan dalam tabel berikut ini :

Tabel 17. Pendapat Responden tentang Keamanan Pelayanan

\begin{tabular}{|c|c|c|c|c|c|}
\hline & & Frequency & Percent & Valid Percent & Cumulative Percent \\
\hline \multirow[t]{4}{*}{ Valid } & Tidak aman & 0 & 0,00 & 0,00 & 0,00 \\
\hline & Kurang aman & 0 & 0,00 & 0,00 & 0,00 \\
\hline & Aman & 98 & 65,33 & 65,33 & 65,33 \\
\hline & Sangat aman & 52 & 34,67 & 34,67 & 100,00 \\
\hline & Total & 150 & 100 & 100 & \\
\hline
\end{tabular}

Sumber : Data primer, diolah 2019

Tabel tersebut di atas menunjukkan bahwa mayoritas responden menyatakan Keamanan Pelayanan di Polres Brebes Aman (65,33\%). Nilai unsur butir pertanyaan tentang keamanan pelayanan sebesar 502 dengan nilai rata rata per unsur sebesar 3,35 X $25=83,67$. Dengan demikian di peroleh Nilai IKM butir pertanyaan tentang Keamanan Pelayanan di Polres Brebes sebesar 83,67 pada kreteria Sangat Baik. Responden merasakan perasaan aman selama dalam pelayanan di Polres Brebes.

\section{Distribusi Data Indeks Kepuasan Masyarakat}

Berdasarkan hasil penelitian diperoleh Nilai Indeks Kepuasan Masyarakat (IKM) dihitung dengan menggunakan nilai rata-rata tertimbang masing-masing lingkup pelayanan. Dalam penghitungan indeks kepuasan masyarakat terhadap 14 lingkup pelayanan yang dikaji. Adapun rincian perhitungan indeks kepuasan masyarakat ini adalah sebagai berikut : 
Jurnal Personalia, Financial, Operasional,

Marketing dau Sistem Informasi

Performance. Volume 27 Nomor 2 Tahun 2020, 62-75

Tabel 18. Perhitungan Indeks Kepuasan Masyarakat (IKM)

\begin{tabular}{clcccc} 
No & \multicolumn{1}{c}{ Lingkup Pelayanan } & $\begin{array}{c}\text { Nilai per } \\
\text { Unsur } \\
\text { Pelayanan }\end{array}$ & $\begin{array}{c}\text { NRR per } \\
\text { Unsur (A) }\end{array}$ & $\begin{array}{c}\text { Bobot } \\
\text { Tertimbang } \\
\text { (B) }\end{array}$ & (A) x (B) \\
\hline 1 & Prosedur pelayanan & 490 & 3,27 & 0,071 & 0,232 \\
2 & Pesyaratan pelayanan & 482 & 3,21 & 0,071 & 0,228 \\
3 & Kejelasan petugas pelayanan & 491 & 3,27 & 0,071 & 0,232 \\
4 & Kedisiplinan petugas pelayanan & 489 & 3,26 & 0,071 & 0,231 \\
5 & Tanggung jawab petugas pelayanan & 491 & 3,27 & 0,071 & 0,232 \\
6 & Kemampuan petugas pelayanan & 502 & 3,35 & 0,071 & 0,238 \\
7 & Kecepatan pelayanan & 467 & 3,11 & 0,071 & 0,221 \\
8 & Keadilan mendapatkan pelayanan & 486 & 3,24 & 0,071 & 0,230 \\
9 & Kesopanan dan keramahan petugas & 502 & 3,35 & 0,071 & 0,238 \\
10 & Kewajaran biaya pelayanan & 475 & 3,17 & 0,071 & 0,225 \\
11 & Kepastian biaya pelayanan & 497 & 3,31 & 0,071 & 0,235 \\
12 & Kepastian jadwal pelayanan & 504 & 3,36 & 0,071 & 0,239 \\
13 & Kenyamanan lingkungan & 492 & 3,28 & 0,071 & 0,233 \\
14 & Keamanan pelayanan & 502 & 3,35 & 0,071 & 0,238 \\
\hline
\end{tabular}

Sumber: Data primer, diolah 2019

Dari tabel 18 tersebut diatas terlihat bahwa nilai kepuasan masyarakat (IKM) diperoleh sebesar 3,252 dan nilai IKM setelah dikonversi $=3,252 \times 25=81,30$. Dengan demikian nilai Indeks Kepuasan Masyarakat (IKM) pelayanan di Polres Brebes sebesar 81,30 dan dikategorikan Sangat Baik.

\section{KESIMPULAN}

Hasil penelitian ini mengungkapkan Indeks Kepuasan Masyarakat di Kepolisian Resor Kabupaten Brebes sebesar 81,30 dan berada pada katagori SANGAT BAIK. Beberapa saran yang dapat penulis sampaikan adalah tata cara pelayanan baik yang menyangkut teknis maupun administrasi termasuk prosedur pelayanan yang dibakukan bagi pemberi dan penerima pelayanan serta tata cara pengaduan, agar disederhanakan sehingga prosedur pelayanan bisa menjadi lebih baik lagi, setiap jenis pelayanan agar lebih ditingkatkan lagi, termasuk waktu pelayanan bisa lebih dipercepat lagi, sehingga dapat memuaskan para pengguna layanan masyarakat pada Polres Brebes, terhadap kewajaran biaya pelayanan yang diberikan oleh pengguna layanan ditindaklanjuti dengan memberikan sosialisasi dan pengguna layanan bisa memperoleh informasi dan penjelasan yang transparan berkaitan dengan rincian biaya yang di bebankan, keadilan mendapatkan pelayanan yang telah di berikan sudah baik dengan melengkapi, menambah dan menyediakan fasilitas layanan diharapkan memberikan keberadilan dalam melaksanakan pelayanan terhadap masyarakat.

\section{DAFTAR PUSTAKA}

Azwar, (2000). Reliabilitas dan Validitas Cetakan Kedua. Yogyakarta: Pustaka Pelajar.

Anwar Ali, (2009). Statistika Untuk Penelitian Pendidikan dan Aplikasinya dengan SPSS dan EXCEL. Kediri: IAIT Press. 
Jurnal Personalia, Financial, Operasional,

Marketing dau Sistem Informasi

Performance. Volume 27 Nomor 2 Tahun 2020, 62-75

Budi Winarno, (2002). Teori dan Proses Kebijakan Publik, Yogyakarta: Media Pressindo.

Estawara, Helpris (2010). StakeholderRelationship IN Intgrated Marketing Communication. Jakarta: Universitas Pancasila.

Jurnal Sinergi, (2004). Kinerja Pelayanan Aparatur Kepolisian tehadap Kepuasan Masyarakat. Vol. 7 No. 1.

Lastriani, E. (2014). Pengaruh Disiplin terhadap Kinerja Anggota Pada Satlantas Polresta Pekanbaru. Jurnal IImiah Ekonomi dan Bisnis Unilak, 11(2), 353-367

Mouw, E. (2013). Kualitas Pelayanan Publik di Daerah. Jurnal UNIERA, 2(2). 92-103.

Pancarudin, Ahkmad. (2019). Pengaruh Citra Kepolisian Dan Pelayanan Terhadap Kepuasan Masyarakat Pada Polres Metro. Jurnal Simplex, Volume 2, Nomor 2.

Purwanto, Erwan Agus dan Dyah Ratih Sulistyastuti. (2007). Metode Penelitian Kuantitatif. Yogyakarta: Gava Media.

Sugiyono. (2017). Metode Penelitian Kuantitatif, Kualitatif, dan R\&D. Bandung : Alfabeta.

Tampubolon (2020). Change Management, Bogor: Mitra Wacana Media.

Tjiptono, F. (2011). Strategi Pemasaran, Edisi ke-2, Yogyakarta: Andi Offset,.

Undang-undang nomor 25 tahun 2009 Tentang Pelayanan Publik 